Article

\title{
Increasing Students' Physical Activity in Function of Social Sustainability: Recommendations from a Social Marketing Perspective
}

\author{
Ines Djokic, Aleksandar Grubor, Nikola Milicevic * and Nenad Djokic \\ Department of Trade, Marketing and Logistics, Faculty of Economics in Subotica, University of Novi Sad, \\ Subotica 24000, Serbia; mines@ef.uns.ac.rs (I.D.); agrubor@ef.uns.ac.rs (A.G.); djokicn@ef.uns.ac.rs (N.D.) \\ * Correspondence: milicevic.nikola@ef.uns.ac.rs; Tel.: +381-21-485-2933
}

Received: 4 March 2020; Accepted: 10 April 2020; Published: 18 April 2020

\begin{abstract}
The role of physical activity for social sustainability, as well as potential for social marketing to contribute to increasing the level of physical activity, are already documented in previous literature. Those considerations may gain additional importance in the context of student population, often confronted with the decrease of the level of physical activity, and in a country with scarce similar researches. The purpose of this study is to identify socio-demographic determinants of Serbian students' physical activity. Physical activity was examined as an ordinal dependent variable (inactive, low-frequency activity, and recommended frequency activity) and an ordered logit model was implemented for examining its relations with students' gender, age, household size, emotional status, accommodation, year of study, and living standard. The results show that $15.7 \%$ of students are inactive, $22.9 \%$ have low-frequency activity, while $61.3 \%$ met the recommended level of physical activity. The average probability of physical activity is larger for male students in comparison to female students. Students with better living standards are also more physically active. Finally, the average probability of physical activity decreases starting from students who live with their families, followed by those who live in a private accommodation, to students who live in a dormitory. Considering the obtained results, recommendations from a social marketing perspective are provided.
\end{abstract}

Keywords: social sustainability; physical activity; social marketing; student population; socio-demographic characteristics; Republic of Serbia

\section{Introduction}

The concern for environmental degradation affected the development of the sustainability concept in the 1960s [1]. In that period, the Organisation for Economic Cooperation and Development (OECD) was established with the purpose to increase employment and achieve sustainable economic growth among member countries. In addition, the International Union for the Conservation of Nature (IUCN) made the declaration, which indicates the possibility of economic growth, without harming the environment [2]. Later, in the 1980s, in the report of the United Nations Commission on Environment and Development (UNCED), sustainable development was defined as "a development that meets the needs of the present without compromising the ability of future generations to meet their own needs" [1] (p. 2). From its beginning till today, the concept of sustainability has evolved, relying on at least three main dimensions: economic, environmental and social [2]. Therefore, besides the concern for economic development and environmental protection, sustainability refers to people's ways of living, which should be healthy and satisfying for communities [3].

Social sustainability can be defined as "a positive condition within communities, and a process within communities that can achieve that condition" [1] (p. 23). In this regard, behaviors that lead to 
poor health, conflicts and emotional distress should be avoided, while all values (such as cultural, family, and knowledge) that contribute to the progress of community, should be protected and nursed [3]. Put differently, "social sustainability means meeting the needs for human well-being" [3] (p. 63).

Although the term wellbeing is rather complex and not easy to define, it is usually related to the fulfilment of human needs [4], which include the physical as well as the emotional and social elements [3]. Among them is exercise [3], i.e., physical activity, which can improve physical and psychological wellbeing [5]. Hereby, relations between physical activity and wellbeing can be explained through its positive effect on health.

Engaging in physical activity can be considered as "one of the primary factors in maintaining sound health in modern society" [6] (p. 116). Its benefits are reflected not only in improving physical health by decreasing risks of diabetes, cardiovascular problems, and various types of cancer, but also in improving mental health by decreasing stress and depression [7].

However, although most of those positive effects are well known, physical inactivity is still one of the biggest health problems worldwide, representing a serious cause of premature death [8]. Contemporary conditions, in which people live and work, have decreased the demand for physical activity, whereby the majority of adults do not perform its sufficient amount required for maintaining good health [6]. In Europe, more than $45 \%$ of inhabitants do not engage in exercise or any sport, while only $7 \%$ exercise on a regular basis at least five-times weekly [7].

The problem of physical inactivity is of a special importance for young adulthood, especially bearing in mind that this maturation period, often followed by starting college and engaging in academic activities, can be very stressful [9]. Hence, several studies pointed to this issue among the student population. The results of the research in the United States, China, and Canada, showed that half or more of university students did not perform sufficient levels of physical activity [10]. According to the same author, this percentage in Australia was $40 \%$, while in Europe, more than two-thirds of students were inactive. The research which included university students from 23 countries [11], also pointed that physical activity was below the recommended levels in a significant portion of respondents. In the research from the Republic of Serbia, the analysis showed that students did not meet the minimum level of moderate physical activity, which is the most productive for a healthy lifestyle [12].

In order to increase students' physical activity levels and thus improve their physical and mental health, it is necessary to change their behavior. Bearing in mind that change in behavior represents the final goal of social marketing [13], the application of its tools is of a special importance in resolving this issue. Analogously to marketing activities in the private sector, social marketing also involves the development of proper strategy, including "considerations of product planning, pricing, communication, distribution, and marketing research" [14] (p. 5). Hence, within social marketing, after studying the target audience, a social idea needs to be "packaged" in accordance to their desires and wants, and special attention should be dedicated to the analysis of buyers' costs (money costs, energy costs, opportunity costs, and psychic costs), the development of communication-persuasion strategy and tactics (advertising, personal selling, publicity, and sales promotion), and the provision of compatible distribution and response channel [14]. The adequate adoption of social marketing can bring many significant benefits, which refer to the following [15]:

- main role in the development and the implementation of the planned program belongs to the target audience;

- the focus of all program elements is on behavior change;

- the efficiency and effectiveness can be ensured by tailoring influence attempts to interests, wants, and needs of specific target audience segments, as well as groups or individuals within them;

- besides the "simple" promotion of the desired behavior benefits, the influence attempts, through the implementation of the four Ps, are directed to decreasing the behavior costs and making the change in behavior easy and popular. 
There are a number of studies about increasing physical activity [16-27], some of them focusing on the student population and the possibilities of social marketing in that process. Some of the social marketing programs for improving physical activity, such as VERB, are marked as successful [22]. Hereby, the already mentioned focus on the target audience in social marketing requires performing market segmentation. The market segmentation presents preconditions for providing recommendations from the aspect of social marketing. The application of market segmentation improves the effectiveness of social marketing's positive influence of physical activity [20]. Market segmentation belongs to social marketing benchmark criteria, whereas the increase of the numbers of those criteria used within the intervention increases the possibility of accomplishing desired behavioral outcomes regarding physical activity $[20,21]$.

Generally, market segmentation can be understood as the identification of individuals or organizations with similar characteristics, with significant implications for determining marketing strategy [28]. In addition, the criteria used for performing market segmentation can be grouped into geographic, demographic, psychographic, and behavioral [29]. Hereby, in previous physical activity determinants researches, it is the social-demographic characteristics that are proven as significant [19,30-38]. Therefore, those characteristics will be used as market segmentation criteria in this research.

Having all previously listed in mind, the following objectives of the research are formulated:

- to explore the influence of socio-demographic characteristics on students' physical activity level in previous research;

- to conduct primary research in Serbia regarding students' physical activity in the context of socio-demographic characteristics;

- to use socio-demographic characteristics in describing profiles of different segments, based on the level of students' physical activity;

- to provide recommendations from a social-marketing perspective.

The obtained results can be significant from several aspects. Firstly, they can contribute to social sustainability issues. Secondly, they can support future similar researches not only in the domestic context, where similar researches are relatively scarce, but in the wider context as well.

\section{Literature Review}

Because of its importance, students' physical activity has been drawing the attention for many years. The researches were conducted in different countries, among different departments, and usually were focused on examining significant physical activity determinants.

For example, physical activity, exercise and sedentary behaviors were analyzed, taking into account demographic variables of students enrolled in conditioning activity classes [30]. Among the others, their results concluded that men had greater levels of exercise and sedentary (TV/videos and computer) activities than women. Considering age, significant relationships between this variable and variables related to sedentary behaviors and physical activities were found as well. Hereby, younger students were more active when it comes to stretching and vigorous intensity activities, while older students spent more time with computers. In addition, the age analysis was also conducted separately for men and women.

Physical activity levels have also been investigated among medicine and nursing students [31]. The results have shown that $48 \%$ and $38 \%$ of surveyed nursing and medicine students, respectively, did not meet recommended physical activity levels. When comparing groups of students with low, moderate and high physical activity levels, significant differences were recorded in age, self-efficiency, benefits to barriers ratio, perceived support, and years of study. On the other hand, significant differences were not detected in perceived stress and gender ratio. In the same research, the application of the linear regression model showed that among eight factors (perceived stress, subject discipline, self-efficiency, 
perceived support, benefits/barriers, gender, age, and year of the degree), only self-efficiency and perceived support had significant positive relationships with the reported level of physical activity.

In another study [32], the physical activity and quality of life (QoL) were examined for sports (SDS) and other department students (ODS). The scores of physical activity and QoL significantly differed between those departments, both in favor to SDS. In regard to gender-specific physical activity levels, significantly higher scores were recorded for men in total, high, medium, and low activities. When it comes to QoL, a significant difference between genders was detected in social relationships, while in other parameters, (physical health, environment, and psychological health) it wasn't the case. Furthermore, the results of the study pointed to the existence of positive relationship between physical activity and QoL levels.

The overall health behavior and its six dimensions, including physical activity, were also examined among Mexican University students at the Psychology School [33]. The subject of the analysis also included their relations with socio-demographic variables. As a separate dimension, physical activity was significantly related to student status, gender, age, marital status, socio-economical level, and mother's education. Hereby, full time students, men, and younger students were more active than part time students, women and students with 25 years or above, respectively. A higher level of physical activity was also recorded for single students, students with a medium-high socio-economic level, and students whose mothers had college education. In addition, when it comes to predicting, the multiple regression model included three variables (gender, marital status, and mother's education), which explained $11.1 \%$ of the total variance of physical activity.

Among the others, the influence of socio-demographic factors (gender, age, mother tongue, marital status, and the mother's and father's educational level) on physical activity was examined as one of the lifestyle behavior indicators [34]. According to the results of the research, which involved Swedish university students, significant relations were reported between physical activity and three out of six analyzed factors (gender, father's, and mother's educational level). When considering gender, male students had a higher physical activity score than female students, while in the case of two other factors, physical activity score was positively related to mother's education and it was highest for students whose fathers had a high school diploma.

Similar to previous research, physical activity was considered in the context of lifestyle behavior [35]. The study, realized among university students in Lebanon, showed that a larger percentage of respondents was physically active. In regard to the type of physical activity, more than a half of them did regular walking or running, while the others did exercise (playing games, aerobics, swimming, weight lifting etc.). As expected, male students had higher physical activity rate opposite to female. Moreover, authors analyzed relations between socio-demographic, environmental and lifestyle behavioral characteristics on one side, and health related quality of life (HRQoL), on the other. Hereby, they pointed to the importance of physical activity as a significant determinant of HRQoL.

Socio-demographic and lifestyle determinants of physical activity practice were also investigated among Spanish university students [36]. Following the obtained results, a significantly larger percent of men engaged in sport or physical activities compared to women. When it comes to food, male students who reported to be physically active ate more fruits, potatoes, rice, pasta, meat, and poultry opposite to physically inactive men. On the other hand, in the case of female students, those who were physically active, in addition to fruits, ate more vegetables and legumes. Body Mass Index (BMI), hours of PC, smoking habit and mother's educational level were important determinants of men's physical activity, while age, hours of TV, smoking habit, alcohol consumption, and mother's physical activity practice were significant determinants of women's physical activity. Besides determinants, the authors analyzed physical activity patterns and reasons for not practicing. For both genders, the main motive to practice physical activity was related to working out, i.e., maintaining their fitness. Other reported motives referred to health, enjoyment, affiliation, and others. Additionally, starting university and lack of time were the main reasons for having stopped practicing and not practicing physical activity, respectively. 
Physical activity was analyzed among Portuguese university students as well [19]. In the study, the attention was dedicated to the effects of day of a week and gender on daily physical activity levels. For recording the number of steps and time spent in sedentary and physical activities, students were carrying an ActiGraph wGT3X-BT accelerometer during seven consecutive days. The results revealed that both male and female students were physically more active during weekdays in comparison to weekend days. From the aspect of gender, statistical differences in physical activity patterns were found only during weekdays in a way that male students spent more time in physical activities than female students, who, on the other hand, spent more sedentary time.

Undergraduate students from one of the U.S. universities were studied when it comes to changes in eating and physical activity behavior during a period of seven semesters [37]. The minority of students exercised at optimal levels during that period, and within it, there is also a significant decrease. The results pointed to the existence of gender differences since men were more likely to engage in physical activity. However, it should be noticed that men were more likely to engage in sedentary activities as well. Furthermore, the research included into consideration students' accommodation. Hereby, living outside of the campus showed negative influence. Nevertheless, it should be stated that students living with parents were excluded from the research.

In another study, students' physical activity motivation was examined by focusing on two types of physical activity: exercise and sport participation [38]. The analysis of the responses of United States college students revealed that intensity and frequency of exercise engaging were greater compared with sport, while adherence and duration of these two physical activity forms were similar. The authors analyzed 14 motivational variables: strength and endurance, appearance, weight management, stress management, positive health, Ill-health avoidance, health pressure, social recognition, competition, challenge, enjoyment, affiliation, nimbleness, and revitalization. When ranking them, positive health was the most important motive for exercise, and competition was the most important for sport participation. The respondents' rates for all motivational variables were examined in the context of mentioned types of physical activity and gender as well.

A number of socio-demographic characteristics are noticed in previous research [19,30-38] — gender, age, living standard, year of study, accommodation, marital status, student status, mother's and father's education, and mother's tongue. In this paper, students' physical activity was analyzed in relation to several socio-demographic variables: gender, age, living standard, emotional status, household size, year of study, and accommodation. Some of the variables listed in studies abroad were not found as appropriate for domestic context-student status, marital status, and mother's tongue, since almost all students are regular, not in a marriage, and with common culture. Parents' education was also not included since their fundamental education was unified in the period of their growing-up. However, we added some variables as well: emotional status and household-size. Having all previously stated in mind, the following model can be presented (Figure 1).

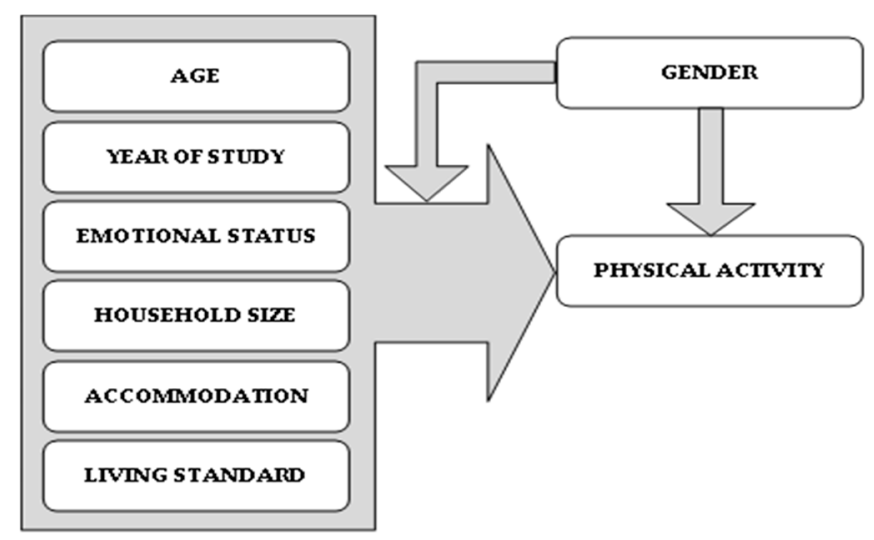

Figure 1. Conceptual model. 
The influences of all the independent variables were considered from the gender aspect as well.

\section{Materials and Methods}

The research based on the convenience sample consisted of 362 students from the University of Novi Sad, Republic of Serbia, and was conducted in 2019 and 2020 (see Table 1).

Table 1. Sample characteristics.

\begin{tabular}{ccc}
\hline & Characteristics & Data \\
\hline \multirow{2}{*}{ Gender } & male & $38.10 \%$ \\
& female & $61.90 \%$ \\
\hline \multirow{2}{*}{ Emotional status } & in a relationship & $46.70 \%$ \\
& not in a relationship & $53.30 \%$ \\
\hline \multirow{2}{*}{ Accommodation } & with family & $39.00 \%$ \\
& student dormitory & $15.70 \%$ \\
& private accommodation & $45.30 \%$ \\
Year of study & first & $28.70 \%$ \\
& second & $13.30 \%$ \\
& third & $25.70 \%$ \\
\hline Age & fourth & $23.50 \%$ \\
\hline Household size & fifth (master) & $8.80 \%$ \\
\hline Living standard & opsen-ended question & $\mathrm{M}=21.46 ; \mathrm{SD}=1.91$ \\
\hline
\end{tabular}

For measuring physical activity, we relied on the item already used in similar research [11] (p. 183) "whether the individual had taken any exercise (e.g., sport, physically active pastime) in the past 2 weeks". Although the active traveling to work or study could also be considered in this context, the contribution of walking and bicycling for the purpose of transportation amongst students to the overall level of physical activity is very small [11] (p. 188), especially when dormitories are located near the students campuses, as is the case with the University of Novi Sad. Hence, in accordance to the criterion of ACSM (American College of Sports Medicine Position Stand), by which the recommended general level of physical activity refers to exercising 3 or more times a week, i.e., 6 times in 2 weeks [11], all respondents have been divided into three groups: inactive, low-frequency activity, and recommended frequency activity. Besides physical activity, the questionnaire included socio-demographic characteristics, among which three of them were continuous (age, household size, and living standard) and four categorical (gender, emotional status, accommodation, and year of study).

Bearing in mind that physical activity was presented through an ordinal variable, an ordered logit model was implemented for examining its relations with socio-demographic characteristics. In addition, for more detailed analysis, the concept of marginal effects [39] was applied as well. Furthermore, in order to distinguish specific segments, predictive probabilities have been calculated for different combinations of analyzed variables (those that had significant relations with physical activity level segments). Data processing was carried out by the use of STATA statistical package.

\section{Results}

Generally, when it comes to the level of physical activity, the results of this research show that $15.7 \%$ of students are inactive, $22.9 \%$ have low-frequency activity, while $61.3 \%$ met the recommended level of physical activity. In addition, the results of a logit model are presented in Table 2. 
Table 2. Logit model.

\begin{tabular}{|c|c|c|c|c|c|c|}
\hline Variables & Coef. & Std. Err. & $\mathbf{z}$ & $P>|z|$ & \multicolumn{2}{|c|}{ [95\% Conf. Interval] } \\
\hline \multicolumn{7}{|l|}{ Gender } \\
\hline female & -0.89 & 0.24 & -3.72 & 0.00 & -1.36 & -0.42 \\
\hline Age & -0.12 & 0.12 & -1.03 & 0.30 & -0.35 & 0.11 \\
\hline \multicolumn{7}{|l|}{ Year of study } \\
\hline 2 nd & -0.39 & 0.38 & -1.01 & 0.31 & -1.13 & 0.36 \\
\hline 3 rd & 0.08 & 0.38 & 0.20 & 0.84 & -0.67 & 0.82 \\
\hline 4 th & 0.21 & 0.57 & 0.36 & 0.72 & -0.91 & 1.32 \\
\hline 5 th & 0.22 & 0.69 & 0.32 & 0.75 & -1.13 & 1.56 \\
\hline \multicolumn{7}{|l|}{ Emotional status } \\
\hline not in a relationship & 0.18 & 0.22 & 0.79 & 0.43 & -0.26 & 0.62 \\
\hline Household size & 0.13 & 0.11 & 1.20 & 0.23 & -0.08 & 0.35 \\
\hline \multicolumn{7}{|l|}{ Accommodation } \\
\hline dormitory & -0.95 & 0.32 & -2.93 & 0.00 & -1.58 & -0.31 \\
\hline private & -0.70 & 0.25 & -2.75 & 0.00 & -1.19 & -0.20 \\
\hline Living standard & 0.44 & 0.13 & 3.28 & 0.00 & 0.18 & 0.71 \\
\hline /cut1 & -3.06 & 2.50 & & & -7.97 & 1.85 \\
\hline /cut2 & -1.71 & 2.50 & & & -6.62 & 3.19 \\
\hline
\end{tabular}

The $p$ value of a model equals 0.00 (Prob $>$ chi2 $=0.00$ ), which confirms its statistical significance at $\mathrm{p}<0.01$. As can be seen, at three (gender, accommodation, and living standard) out of seven independent variables, coefficients are statistically significant with $p$ lower than 0.01 .

In regard to the living standard, the obtained result (0.44) points to the existence of positive relation between this variable and students' physical activity. Therefore, it can be concluded that students with a better living standard are more physically active.

As two other independent variables with significant coefficients are categorical, we extended the analysis with the concept of marginal effects. The results related to gender are presented in Figure 2.

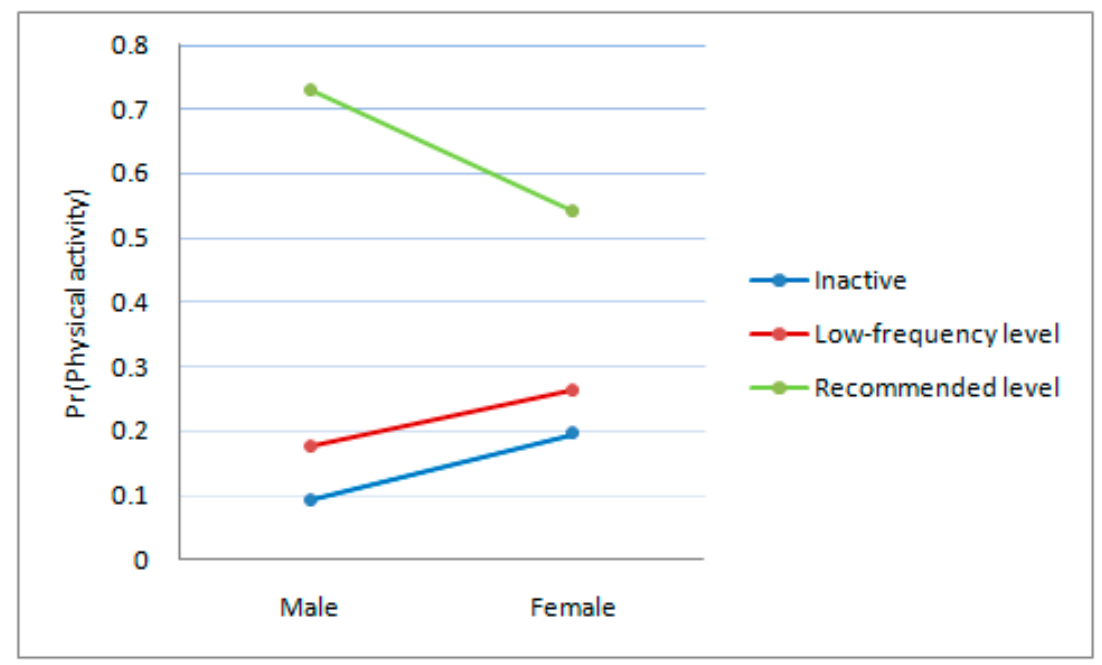

Figure 2. Predictive margins-gender.

In the case of inactive and low-frequency levels, the average probabilities are larger for female students (0.19 and 0.26$)$ in comparison to male students ( 0.09 and 0.18$)$, whereby their differences of 0.10 (for inactive) and 0.08 (for low-frequency level) are statistically significant with $p<0.01$. On the other hand, in the case of recommended level of physical activity, the average probability for male 
students (0.73) is higher than the average probability for female students (0.54), with a statistically significant difference of 0.19 .

When it comes to the accommodation (Figure 3), the highest average probabilities for inactive and low-frequency levels of physical activity were obtained for students who live in a dormitory $(0.22$ and $0.27)$, followed by those who live in a private accommodation ( 0.18 and 0.25$)$, and those who live with their families (0.10 and 0.19). Contrarily, the average probability for the recommended level of physical activity was the highest for students who live with their families (0.71), followed by two other student categories, those who live in a private accommodation (0.57), and those who live in a dormitory $(0.51)$.

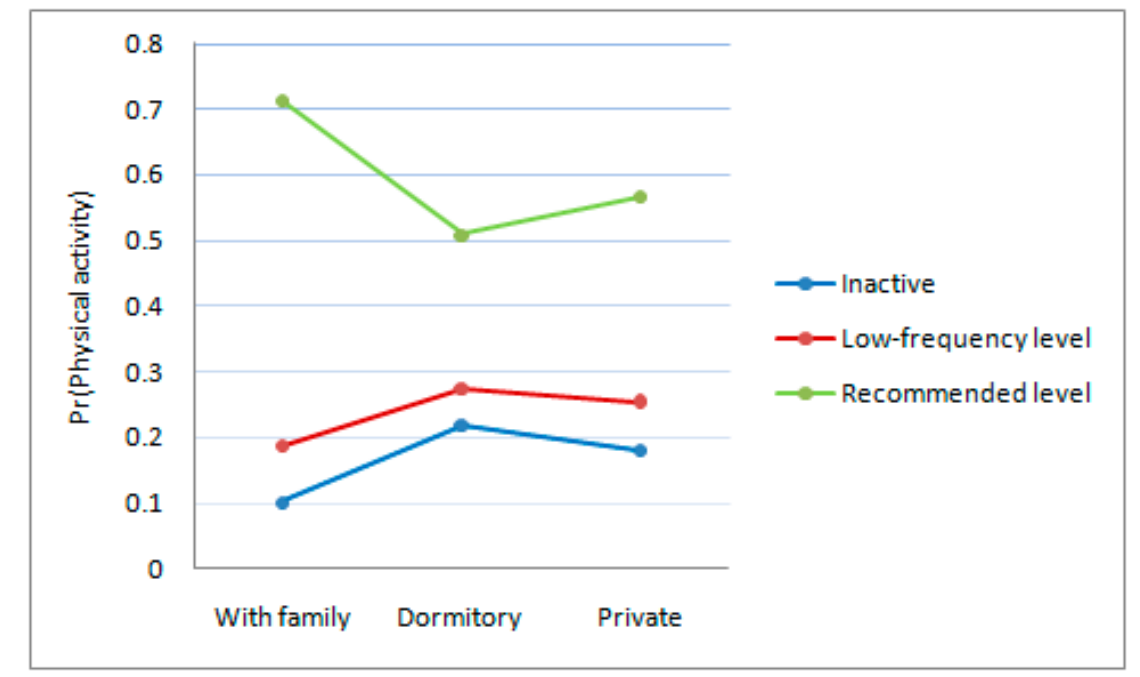

Figure 3. Predictive margins-accommodation.

In addition, the differences in average probabilities of physical activity between these three groups have been examined for all three segments as well. They are shown in Table 3.

Table 3. Marginal effects-accommodation.

\begin{tabular}{cccccccc}
\hline \multirow{2}{*}{ Accommodation } & \multicolumn{2}{c}{ Inactive } & \multicolumn{2}{c}{ Low-Frequency Level } & \multicolumn{2}{c}{ Recommended Level } \\
\cline { 3 - 8 } & & $\mathbf{d y} / \mathbf{d x}$ & $\mathbf{P}>\mathbf{z} \mid$ & $\mathbf{d y} / \mathbf{d x}$ & $\mathbf{P}>|\mathbf{z}|$ & $\mathbf{d y} / \mathbf{d x}$ & $\mathbf{P}>|\mathbf{z}|$ \\
\hline \multirow{2}{*}{ With family } & dormitory & 0.12 & 0.01 & 0.08 & 0.00 & -0.20 & 0.00 \\
& private & 0.08 & 0.00 & 0.06 & 0.01 & -0.14 & 0.00 \\
\hline \multirow{2}{*}{ Dormitory } & with family & -0.12 & 0.01 & -0.08 & 0.00 & 0.20 & 0.00 \\
& private & -0.04 & 0.41 & -0.02 & 0.38 & 0.06 & 0.40 \\
\hline \multirow{2}{*}{ Private } & with family & -0.08 & 0.00 & -0.06 & 0.01 & 0.14 & 0.00 \\
& dormitory & 0.04 & 0.41 & 0.02 & 0.38 & -0.06 & 0.40 \\
\hline
\end{tabular}

The differences in average probabilities for all three segments based on physical activity between students who live with their families and two other groups are statistically significant, with $\mathrm{p}<0.01$. On the other hand, the $\mathrm{p}$ values for differences in average probabilities between students who live in a dormitory and those who live in a private accommodation were higher than 0.05 in all three physical activity segments. The results considering the influence of independent variables from the gender aspect are shown in Table 4. 
Table 4. Marginal effects-gender aspect.

\begin{tabular}{|c|c|c|c|c|c|c|c|}
\hline \multirow{2}{*}{ Physical Activity } & \multirow{2}{*}{ Gender } & \multicolumn{2}{|c|}{ Inactive } & \multicolumn{2}{|c|}{ Low-Frequency Level } & \multicolumn{2}{|c|}{ Recommended Level } \\
\hline & & $\mathrm{dy} / \mathrm{dx}$ & $\mathbf{P}>|z|$ & $\mathrm{dy} / \mathrm{dx}$ & $P>|z|$ & $\mathrm{dy} / \mathrm{dx}$ & $P>|z|$ \\
\hline \multirow{2}{*}{ Age } & male & 0.01 & 0.30 & 0.01 & 0.30 & -0.02 & 0.30 \\
\hline & female & 0.02 & 0.30 & 0.01 & 0.30 & -0.03 & 0.30 \\
\hline \multicolumn{8}{|l|}{ Year of study } \\
\hline \multirow{2}{*}{ 2nd } & male & 0.04 & 0.31 & 0.04 & 0.32 & -0.08 & 0.31 \\
\hline & female & 0.06 & 0.31 & 0.02 & 0.36 & -0.09 & 0.31 \\
\hline \multirow{2}{*}{3 rd } & male & -0.01 & 0.84 & -0.01 & 0.89 & 0.01 & 0.84 \\
\hline & female & -0.01 & 0.84 & -0.01 & 0.84 & 0.02 & 0.84 \\
\hline \multirow{2}{*}{4 th } & male & -0.02 & 0.72 & -0.02 & 0.71 & 0.04 & 0.71 \\
\hline & female & -0.03 & 0.72 & -0.02 & 0.71 & 0.05 & 0.71 \\
\hline \multirow{2}{*}{ 5th } & male & -0.02 & 0.75 & -0.02 & 0.75 & 0.04 & 0.75 \\
\hline & female & -0.03 & 0.75 & -0.02 & 0.75 & 0.05 & 0.75 \\
\hline \multirow{2}{*}{ Not in a relationship } & male & -0.01 & 0.43 & -0.02 & 0.43 & 0.03 & 0.43 \\
\hline & female & -0.03 & 0.43 & -0.01 & 0.43 & 0.04 & 0.43 \\
\hline \multirow{2}{*}{ Household size } & male & -0.01 & 0.24 & -0.01 & 0.23 & 0.02 & 0.23 \\
\hline & female & -0.02 & 0.23 & -0.01 & 0.23 & 0.03 & 0.23 \\
\hline \multicolumn{8}{|l|}{ Accommodation } \\
\hline \multirow{2}{*}{ dormitory } & male & 0.08 & 0.02 & 0.10 & 0.00 & -0.18 & 0.01 \\
\hline & female & 0.14 & 0.01 & 0.08 & 0.00 & -0.22 & 0.00 \\
\hline \multirow{2}{*}{ private } & male & 0.05 & 0.01 & 0.07 & 0.01 & -0.12 & 0.01 \\
\hline & female & 0.09 & 0.00 & 0.06 & 0.01 & -0.16 & 0.00 \\
\hline \multirow{2}{*}{ Living standard } & male & -0.04 & 0.00 & -0.04 & 0.00 & 0.08 & 0.00 \\
\hline & female & -0.06 & 0.00 & -0.03 & 0.00 & 0.10 & 0.00 \\
\hline
\end{tabular}

As can be seen in Table 4, there are no larger differences in their values between male and female. Predictive probabilities for different combinations of significant independent variables can be seen in Table 5.

Table 5. Predictive margins-combinations.

\begin{tabular}{|c|c|c|c|c|c|c|c|c|}
\hline \multicolumn{3}{|c|}{ Variables } & \multicolumn{2}{|c|}{ Inactive } & \multicolumn{2}{|c|}{ Low-Frequency Level } & \multicolumn{2}{|c|}{ Recommended Level } \\
\hline Gender & Accommodation & Living Standard & Margin & $P>|z|$ & Margin & $P>|z|$ & Margin & $P>|z|$ \\
\hline male & with family & 1 & 0.17 & 0.01 & 0.27 & 0.00 & 0.55 & 0.00 \\
\hline male & with family & 2 & 0.12 & 0.00 & 0.22 & 0.00 & 0.66 & 0.00 \\
\hline male & with family & 3 & 0.08 & 0.00 & 0.17 & 0.00 & 0.75 & 0.00 \\
\hline male & with family & 4 & 0.05 & 0.00 & 0.12 & 0.00 & 0.82 & 0.00 \\
\hline male & with family & 5 & 0.03 & 0.00 & 0.09 & 0.00 & 0.88 & 0.00 \\
\hline male & dormitory & 1 & 0.35 & 0.00 & 0.32 & 0.00 & 0.33 & 0.00 \\
\hline male & dormitory & 2 & 0.26 & 0.00 & 0.31 & 0.00 & 0.43 & 0.00 \\
\hline male & dormitory & 3 & 0.18 & 0.00 & 0.28 & 0.00 & 0.54 & 0.00 \\
\hline male & dormitory & 4 & 0.13 & 0.00 & 0.23 & 0.00 & 0.64 & 0.00 \\
\hline male & dormitory & 5 & 0.08 & 0.00 & 0.18 & 0.00 & 0.74 & 0.00 \\
\hline male & private & 1 & 0.30 & 0.00 & 0.32 & 0.00 & 0.38 & 0.00 \\
\hline male & private & 2 & 0.21 & 0.00 & 0.29 & 0.00 & 0.49 & 0.00 \\
\hline male & private & 3 & 0.15 & 0.00 & 0.25 & 0.00 & 0.60 & 0.00 \\
\hline male & private & 4 & 0.10 & 0.00 & 0.20 & 0.00 & 0.70 & 0.00 \\
\hline male & private & 5 & 0.07 & 0.00 & 0.15 & 0.00 & 0.78 & 0.00 \\
\hline female & with family & 1 & 0.34 & 0.00 & 0.32 & 0.00 & 0.34 & 0.00 \\
\hline female & with family & 2 & 0.25 & 0.00 & 0.31 & 0.00 & 0.44 & 0.00 \\
\hline female & with family & 3 & 0.18 & 0.00 & 0.27 & 0.00 & 0.55 & 0.00 \\
\hline female & with family & 4 & 0.12 & 0.00 & 0.22 & 0.00 & 0.66 & 0.00 \\
\hline female & with family & 5 & 0.08 & 0.00 & 0.17 & 0.00 & 0.75 & 0.00 \\
\hline female & dormitory & 1 & 0.57 & 0.00 & 0.26 & 0.00 & 0.17 & 0.01 \\
\hline female & dormitory & 2 & 0.46 & 0.00 & 0.30 & 0.00 & 0.24 & 0.00 \\
\hline female & dormitory & 3 & 0.35 & 0.00 & 0.32 & 0.00 & 0.32 & 0.00 \\
\hline female & dormitory & 4 & 0.26 & 0.00 & 0.31 & 0.00 & 0.43 & 0.00 \\
\hline female & dormitory & 5 & 0.18 & 0.00 & 0.28 & 0.00 & 0.54 & 0.00 \\
\hline female & private & 1 & 0.51 & 0.00 & 0.29 & 0.00 & 0.20 & 0.00 \\
\hline female & private & 2 & 0.40 & 0.00 & 0.31 & 0.00 & 0.29 & 0.00 \\
\hline female & private & 3 & 0.30 & 0.00 & 0.32 & 0.00 & 0.38 & 0.00 \\
\hline female & private & 4 & 0.21 & 0.00 & 0.29 & 0.00 & 0.49 & 0.00 \\
\hline female & private & 5 & 0.15 & 0.00 & 0.25 & 0.00 & 0.60 & 0.00 \\
\hline
\end{tabular}


When it comes to the inactive category, the highest average probability (0.57) refers to female students who live in a dormitory, with low living standard (1 out of 5). As for students with low frequent level of exercise, there are several profiles with an average probability of higher than 0.30 to belong to this segment: female, living with families, assessing standard with 1 or 2 , female living privately with standard marked with 2 or 3 , female living at dormitory, with living standard assessed with 3 and 4, male living in dormitory with assessed standard of 1 and 2, male living privately and evaluating standard with 1 . The largest probability $(0.88)$ to be active can be noticed for men, living with families and assessing standard with 5.

\section{Discussion and Conclusions}

When it comes to the level of Serbian students' physical activity, it should be noticed that $15.70 \%$ of students are inactive, $22.90 \%$ have low-frequency activity, while $61.30 \%$ meet the recommended level of physical activity. The results suggest that almost $40 \%$ of the students exercised less than six times in two weeks before the interviewing. Those relatively negative tendencies are partly in accordance to the previously described situation worldwide [7,10,11], as well as in Serbia [12].

Having previous results in mind, as well as the significance of physical activity for social sustainability, some general recommendations can be provided. Positive influence of celebrity endorsers are already proven in the literature especially when they are famous because of sport [16]. In the concrete case, trying to cooperate with Novak Djokovic could be a good idea. He is, at the moment of writing this paper, the world tennis player number one at ATP list, and is also Serbian and very popular within the country. When it comes to suggestions regarding student population, there can often be identified the stress on education: "changes to current college physical education programs" [6] (p. 124), "paying attention to the health education and the behaviors related to the health promotion" [17] (p. 205). However, if relying dominantly on the university in that process, the special caution should be paid at implementation of intervention measures [18]. Some other recommendations rely on providing low-cost programs of physical activity or bicycles [19].

However, in addition to general recommendations, within this research is conducted market segmentation. Not only that the research is focused on a specific segment of population, but it is additionally segmented regarding socio-demographic characteristics. The obtained results can be compared to some of the previous research. Hereby, out of seven independent variables-students' gender, age, household size, emotional status, accommodation, year of study and living standard, only three had significant influence, two of them at 0.10 level. The three variables that had significant influence are gender, accommodation, and living standard. Concretely, the average probability of physical activity is larger for male students in comparison to female students. That is in accordance with the results of some previous studies [19,30,32-37]. On the other hand, the existence of gender differences is not always confirmed in the literature [31]. Furthermore, the students with better living standard are also more physically active, what is in accordance to previous research [33]. Finally, the average probability of physical activity decreases starting from students who live with their families, followed by those who live in a private accommodation, to the students who live in a dormitory. The existence of the difference in the context of students' accommodation is in line with some of the authors [37], although their results are in favor of living on the campus. However, the comparability of the results is limited due to exclusion of students living with parents from their research. The highest activity of students living with parents in this research can be explained by the smallest change in life when started studying in comparison to other segments, and having the largest amount of free time because of relying on parents for performing certain activities in the house.

Contrarily, students' age, household size, emotional status, and year of study are not proven as significant predictors of physical activity in this research. The absence of the influence of age is in line with the studies [31] (when applying linear regression model) [34], but is not in accordance to other studies $[30,33,36]$ (in the last case, for females). The lack of influence of the year of study is in 
accordance to [31] (when applying linear regression model), but not with [37]. Emotional status not influencing physical activity was proven in this research in line with [34], but in contrast to [33].

The description of the profiles of marketing segments led to several conclusions. Firstly, the greatest probability to be inactive can be noticed in the case of women living in dormitories and having very low living standard. However, weakly active students belong in most of the cases of women, living in different places, and assessing living standard with lower and higher marks. When men belong to this segment, they always have low standard and do not live with their families. Finally, most physically active are men living with families and have high living standard.

Starting from the descriptions of the segments, there is a need to target each of them. In the case of active students, the stress should be on maintaining their level of activity. When it comes to students being less active or inactive, they should be tried to be translated to more active segments in each of the cases.

From the context of marketing mix, several recommendations can be provided. As a starting point can be used, the means-end approach to consumer behavior, meaning consumers are not interested in products per se, but are interested in them regarding the way the product helps them attain their life values [40]. Hereby, physical activity can be presented as a mean for accomplishing different ends. Having in mind that it is the case of younger population, there is a great possibility (although additional studies should confirm this hypothesis) that being healthy is still not the primary focus of their interest, since it is usually immanent to their age. However, "being attractive" or "having a good time with friends" or "being interesting and adventurous" or "being strong and successful" can be of more interest to them and motivate them to spend their time in accomplishing those goals. Launching a campaign named, for example, "People inspired with me" (with ambiguous meaning-being inspired together or being inspired by) and asking the students to post Instagram photos when having physical activity with friends can fulfill if not all, but most of the listed goals. Providing equipment for being active can be of special importance-free bicycles, gyms under the open sky, balls for different sports, or even walking routes. As a part of the campaign, the participants can be given designed shirts or hats. Besides, the number of likes could be understood as non-monetary incentive. An application offering students information about places nearby where they can accomplish "being attractive," "having a good time with friends," "being interesting and adventurous," or "being strong and successful" by being physically active and having content available at those places could also be helpful. Engaging students from faculty of sport to show other students different options of physical activity might be useful. In addition to using social networks, direct contact with a target audience is possible. From the beginning of the studies, faculties could provide students information about accomplishing quality of life, including possibilities of performing physical activities. Such information could increase the popularity of the faculties and bring them more interested students, with whom communication can be performed by using, among others, e-mail marketing in accordance to permission marketing approach [41].

Some of the recommendations from researches abroad might be appropriate to be implemented in domestic conditions, as well, especially in the case of students' segments being less physically active. For example, bearing in mind that for people with a lower living standard, certain physical activity contents are less accessible, they can be attracted with incentives in the first period of intervention (free period, novel activities). Informing them about it can be done in a classical manner, since in the subsequent phases, there would be increasing influence of word-of-mouth, which is expected to be stronger if the number of participants recruited at the beginning was larger [23]. Community-based interventions had a positive effect not only in case of population with lower living standard [23,24], but for women as well [25]. Wearable technology is already proven to be successful for increasing physical activity of women [26], so it might be appropriate to inform them how to measure the level of their physical activity by using disposable technology. In this regard, activities of ambush marketing, to which attention is being paid in domestic conditions as well, can be used [42]. For example, under the billboard which promotes some possibility of physical activity, there could be added information about disposable free wearable technology. 
It should be noticed that communication with all those segments can be performed directly, and by using online and offline marketing communication channels. The possibilities of identifying such segments on social networks are great. Besides leaving the information about the gender when creating profiles, the living standard can often be predicted considering the devices by which is being logged-in to profiles, while at the same time information about changing the place of living are also available, together with frequent check-ins at certain places, including dormitories. However, there should be taken into account conclusions from previous research that "solely Web-based intervention seems to be ineffective in promoting PA among universities students" and that "face-to-face lifestyle modification interventions have greater effects than Web-based interventions" [27] (p. 1608). Finally, considering a social marketing approach, it is of great importance to provide adequate monitoring regarding all previously described issues.

Future research may measure physical activity more precisely, include other determinants in addition to socio-demographic (especially lifestyle), reach larger and more representative sample, and monitor the participants through time. In addition, consultations with representatives of the country/city/university/sponsors could be performed in advance for obtaining their opinion about suggested intervention.

Author Contributions: All of the authors formulated goals of the research and interpreted available literature; conducting and analyzing research was performed by N.M. and N.D., while implications were developed by I.D. and A.G. All authors have read and agreed to the published version of the manuscript.

Funding: This research received no external funding.

Conflicts of Interest: The authors declare no conflicts of interest.

\section{References}

1. McKenzie, S. Social Sustainability: Towards Some Definitions; Working Paper Series No 27; Hawke Research Institute, University of South Australia: Magill, South Australia, 2004.

2. Opp, S.M. The forgotten pillar: A definition for the measurement of social sustainability in American cities. Local Environ. 2016, 22, 286-305. [CrossRef]

3. Rogers, D.S.; Duraiappah, A.K.; Antons, D.C.; Munoz, P.; Bai, X.; Fragkias, M.; Gutscher, H. A vision for human well-being: Transition to social sustainability. Curr. Opin. Environ. Sustain. 2012, 4, 61-73. [CrossRef]

4. Helne, T.; Hirvilammi, T. Wellbeing and Sustainability: A Relational Approach. Sustain. Dev. 2015, 23, 167-175. [CrossRef]

5. Reynolds, F. Strategies for Facilitating Physical Activity and Wellbeing: A Health Promotion Perspective. Br. J. Occup. Ther. 2001, 64, 330-336. [CrossRef]

6. Keating, X.D.; Guan, J.; Piñero, J.C.; Bridges, D.M. A Meta-Analysis of College Students Physical Activity Behaviors. J. Am. Coll. Health 2005, 54, 116-126. [CrossRef] [PubMed]

7. World Health Organization. Physical Activity Factsheets for the 28 European Union Member States of the WHO European Region; WHO Regional Office for Europe: Copenhagen, Denmark, 2018.

8. Buchan, D.S.; Ollis, S.; Thomas, N.E.; Baker, J.S. Physical Activity Behaviour: An Overview of Current and Emergent Theoretical Practices. J. Obes. 2012, 2012, 1-11. [CrossRef] [PubMed]

9. Nguyen-Michel, S.T.; Unger, J.B.; Hamilton, J.; Spruijt-Metz, D. Associations between physical activity and perceived stress/hassles in college students. Stress Health 2006, 22, 179-188. [CrossRef]

10. Irwin, J.D. Prevalence of University Students Sufficient Physical Activity: A Systematic Review. Percept. Mot. Ski. 2004, 98, 927-943. [CrossRef]

11. Haase, A.; Steptoe, A.; Sallis, J.F.; Wardle, J. Leisure-time physical activity in university students from 23 countries: Associations with health beliefs, risk awareness, and national economic development. Prev. Med. 2004, 39, 182-190. [CrossRef]

12. Malčić, B.; MarićJurišin, S. Fizička aktivnost studenata univerziteta u Novom Sadu—Realnost i perspektive. SPORT Nauka i Praksa 2018, 8, 13-26.

13. Dibb, S. Up, up and away: Social marketing breaks free. J. Market. Manag. 2014, 30, 1159-1185. [CrossRef]

14. Kotler, P.; Zaltman, G. Social Marketing: An Approach to Planned Social Change. J. Market. 1971, 35, 3-12. [CrossRef] 
15. Andreasen, A.R. Marketing Social Marketing in the Social Change Marketplace. J. Public Policy Market. 2002, 21, 3-13. [CrossRef]

16. Behnoosh, S.; Naylor, M.; Dickson, G. Promoting sport and physical activity participation: The impact of endorser expertise and recognisability. Manag. Sport Leis. 2017, 22, 214-233. [CrossRef]

17. Moghaddam, F.; Norouzi, S.; Norouzi, M.; Norouzi, A.; Neisary, Z. Evaluation of Lifestyle Health Promotion of Dormitory Medical Students Regarding Comprehensive Aspects. Crescent J. Med. Biol. Sci. 2017, 4, 205-210.

18. Okely, A.D.; Lubans, D.R.; Morgan, P.J.; Cotton, W.; Peralta, L.; Miller, J.; Batterham, M.; Janssen, X. Promoting physical activity among adolescent girls: The Girls in Sport group randomized trial. Int. J. Behav. Nutr. Phys. Act. 2017, 14, 81-94. [CrossRef]

19. Clemente, F.M.; Nikolaidis, P.T.; Martins, F.M.L.; Mendes, R.S. Physical Activity Patterns in University Students: Do They Follow the Public Health Guidelines? PLoS ONE 2016, 11, e0152516. [CrossRef]

20. Kubacki, K.; Ronto, R.; Lahtinen, V.; Pang, B.; Rundle-Thiele, S. Social marketing interventions aiming to increase physical activity among adults. Health Educ. 2017, 117, 69-89. [CrossRef]

21. Xia, Y.; Deshpande, S.; Bonates, T. Effectiveness of Social Marketing Interventions to Promote Physical Activity Among Adults: A Systematic Review. J. Phys. Act. Health 2016, 13, 1263-1274. [CrossRef]

22. Huhman, M.; Kelly, R.P.; Edgar, T. Social Marketing as a Framework for Youth Physical Activity Initiatives: A 10-Year Retrospective on the Legacy of CDC's VERB Campaign. Curr. Obes. Rep. 2017, 6, 101-107. [CrossRef]

23. Withall, J.; Jago, R.; Fox, K.R. The effect a of community- based social marketing campaign on recruitment and retention of low-income groups into physical activity programmes-A controlled before-and-after study. BMC Public Health 2012, 12, 836-850. [CrossRef] [PubMed]

24. Buscail, C.; Menai, M.; Salanave, B.; Daval, P.; Painsecq, M.; Lombrail, P.; Hercberg, S.; Chantal, J. Promoting physical activity in a low-income neighborhood of the Paris suburb of Saint-Denis: Effects of a communitybased intervention to increase physical activity. BMC Public Health 2016, 16, 667-675. [CrossRef] [PubMed]

25. Wen, L.M.; Thomas, M.; Jones, H.; Orr, N.; Moreton, R.; King, L.; Hawe, P.; Bindon, J.; Humphries, J.; Schicht, K.; et al. Promoting physical activity in women: Evaluation of a 2-year community-based intervention in Sydney, Australia. Health Promot. Int. 2002, 17, 127-137. [CrossRef] [PubMed]

26. Arigo, D. Promoting physical activity among women using wearable technology and online social connectivity: A feasibility study. Health Psychol. Behav. Med. 2015, 3, 391-409. [CrossRef]

27. Maselli, M.; Ward, P.B.; Gobbi, E.; Carraro, A. Promoting Physical Activity Among University Students: A Systematic Review of Controlled Trials. Am. J. Health Promot. 2018, 32, 1602-1612. [CrossRef]

28. Fahy, J.; Jobber, D. Osnovi Marketinga; Data Status: Belgrade, Republic of Serbia, 2006.

29. Kolter, K.; Keller, K.L. Marketing Menadžment; Data Status: Belgrade, Republic of Serbia, 2006.

30. Buckworth, J.; Nigg, C. Physical Activity, Exercise, and Sedentary Behavior in College Students. J. Am. Coll. Health 2004, 53, 28-34. [CrossRef]

31. Blake, H.; Stanulewicz, N.; Mcgill, F. Predictors of physical activity and barriers to exercise in nursing and medical students. J. Adv. Nurs. 2017, 73, 917-929. [CrossRef]

32. Çiçek, G. Quality of Life and Physical Activity among University Students. Universal J. Educ. Res. 2018, 6, 1141-1148. [CrossRef]

33. Ulla Díez, S.; Pérez-Fortis, A. Socio-demographic predictors of health behaviors in Mexican college students. Health Promot. Int. 2009, 25, 85-93. [CrossRef]

34. Schmidt, M. Predictors of Self-rated Health and Lifestyle Behaviours in Swedish University Students. Global J. Health Sci. 2012, 4, 1-14. [CrossRef]

35. Sabbah, I.; Sabbah, H.; Khamis, R.; Sabbah, S.; Droubi, N. Health related quality of life of university students in Lebanon: Lifestyles behaviors and socio-demographic predictors. Health 2013, 5, 1-12. [CrossRef]

36. Romaguera, D.; Tauler, P.; Bennasar, M.; Pericas, J.; Moreno, C.; Martinez, S.; Aguilo, A. Determinants and patterns of physical activity practice among Spanish university students. J. Sports Sci. 2011, 29, 989-997. [CrossRef] [PubMed]

37. Small, M.; Bailey-Davis, L.; Morgan, N.; Maggs, J. Changes in Eating and Physical Activity Behaviors Across Seven Semesters of College. Health Educ. Behav. 2012, 40, 435-441. [CrossRef] [PubMed] 
38. Kilpatrick, M.; Hebert, E.; Bartholomew, J. College Students' Motivation for Physical Activity: Differentiating Men's and Women's Motives for Sport Participation and Exercise. J. Am. Coll. Health 2005, 54, 87-94. [CrossRef]

39. Williams, R. Using the margins command to estimate and interpret adjusted predictions and marginal effects. Stata J. 2012, 12, 308-331. [CrossRef]

40. Reynolds, T.J.; Olson, J.C. Understanding Consumer Decision Making: The Means-end Approach to Marketing and Advertising Strategy; Lawrence Erlbaum Associates: Mahwah, NJ, USA, 2001.

41. Grubor, A.; Djokic, N.; Milićević, N. The Use of E-mail Marketing in Accordance with Permission Marketing Approach in Promotion of a Study Program. Strateg. Manag. 2018, 23, 26-31. [CrossRef]

42. Starčević, S.; Majdarević, A.; Marinković, E. Implementation of Ambush Marketing Strategy. Ann. Fac. Econ. Subot. 2018, 40, 49-65. [CrossRef]

(C) 2020 by the authors. Licensee MDPI, Basel, Switzerland. This article is an open access article distributed under the terms and conditions of the Creative Commons Attribution (CC BY) license (http://creativecommons.org/licenses/by/4.0/). 